\title{
Bone regeneration of demineralized dentin matrix with platelet-rich fibrin and recombinant human bone morphogenetic protein-2 on the bone defects in rabbit calvaria
}

Beom-Jin Kim², Seok-Kon Kim² and Jae-Hoon Lee ${ }^{3^{*}}$ (i)

\begin{abstract}
Background: This study was to evaluate the bone formation ability of demineralized dentin matrix (DDM) combined with platelet-rich fibrinogen (PRF) and DDM combined with recombinant human bone morphogenetic protein-2 (rhBMP-2) to improve the osteoinductive ability of DDM.

Methods: After four bone defects with a diameter of $8 \mathrm{~mm}$ were created in the calvarium of each rabbit, DDM was grafted into the first defect (experimental groups 1), a combination of DDM and PRF was grafted into the second defect (experimental groups 2), and DDM with absorbed rhBMP-2 was grafted into the third defect (experimental groups 3). The fourth defect was used as the control group. Twelve healthy male rabbits (New Zealand, white rabbits) weighing around 3.0-4.0 kg were used. Among 12 rabbits, 3 rabbits were sacrificed immediately after surgery and at 2, 4, and 8 weeks after surgery, respectively. Histopathologic analysis and histomorphometric analysis were conducted to evaluate bone formation in each group.

Results: The PRF/DDM group did not show a significantly higher degree of new bone formation in calvarial bone defects than the DDM group at 2, 4, and 8 weeks postoperatively in histopathological findings and histomorphometric results. On the other side, the rhBMP-2/DDM group showed higher degrees of new bone formation and calcification, and the lamellae of bone matrix, which are observed in mature bone tissue, were more distinctly visible in the rhBMP-2/DDM group. Moreover, the rhBMP-2/DDM group showed a significantly higher amount of new bone formation, compared to the DDM group at 4 and 8 weeks postoperatively $(P<0.05)$ in histomorphometric results.
\end{abstract}

Conclusion: The DDM has great potential as a carrier for the maintenance and sustained release of rhBMP-2, which has been recently receiving wide attention as a type of signaling molecules to promote bone formation.

Keywords: Demineralized dentin matrix (DDM), Platelet-rich fibrinogen (PRF), Recombinant human bone morphogenetic protein-2 (rhBMP-2)

\footnotetext{
* Correspondence: lee201@dankook.ac.kr

${ }^{3}$ Department of Oral and Maxillofacial Surgery, College of Dentistry, Dankook University, 119, Dandae-ro, Dongnam-gu, Cheonan-si, Chungcheongnam-do 31116, Republic of Korea

Full list of author information is available at the end of the article
}

\section{Springer Open}

(c) The Author(s). 2021 Open Access This article is licensed under a Creative Commons Attribution 4.0 International License, which permits use, sharing, adaptation, distribution and reproduction in any medium or format, as long as you give appropriate credit to the original author(s) and the source, provide a link to the Creative Commons licence, and indicate if changes were made. The images or other third party material in this article are included in the article's Creative Commons licence, unless indicated otherwise in a credit line to the material. If material is not included in the article's Creative Commons licence and your intended use is not permitted by statutory regulation or exceeds the permitted use, you will need to obtain permission directly from the copyright holder. To view a copy of this licence, visit http://creativecommons.org/licenses/by/4.0/. 


\section{Background}

Continuous research efforts have been made to develop alternatives to existing bone grafting materials or to improve the bone formation ability of existing bone grafting materials.

Demineralized dentin matrix (DDM), which is a material produced by extracting bone components from extracted autogenous teeth, is a graft material developed based on the fact that teeth and bones are almost identical in chemical composition [1-4].

In addition, there are signaling molecules to promote the bone formation ability, such as platelet-derived growth factors (PDGF) $[5,6]$, bone morphogenetic proteins (BMP) [7], transforming growth factors (TGF- $\beta$ ) [8], epidermal growth factors (EGF), and fibroblast growth factors (FGF), and studies on these materials have been actively conducted.

Platelet-rich plasma (PRP) has been used in the treatment of thrombocytopenia, and as platelet concentrates have been locally applied to surgical sites, PRP is currently used as a term which refers to all types of autologous plasma including a platelet concentrate. Earlier, fibrinogen contained in PRP was obtained from human plasma of one or multiple donors, so there was a risk of HIV infection or hepatitis $\mathrm{C}$ transmission. In addition, thrombin, which is used in the production process of fibrin glue, is also derived from cattle, so the risk of transmission of diseases, including mad cow disease, has been reported $[9,10]$. To address these risks, platelet-rich fibrin (PRF), in which autologous thrombin is concentrated in autologous fibrinogen without the addition of bovine thrombin or an anticoagulant agent, started to be used [11-13].

The bone morphogenetic protein (BMP) refers to a group of peptide growth factors belonging to the superfamily of transforming growth factors (TGFs) and acts on interstitial cells in mammals to promote cell differentiation into osteocytes and chondrocytes. In 1965 and 1971, Urist [14, 15] extracted the substance from the demineralized bone matrix and named it bone morphogenetic protein (BMP). To date, 15 types of BMPs from BMP-1 to BMP-15 have been identified, and among them, BMP-2, BMP-3, BMP-4, BMP-6, and BMP-7 have been found to induce bone formation [16, 17]. In particular, BMP-2 increases the activity of alkaline phosphatase and has been shown to effectively stimulate bone formation experimentally and clinically in the bone defect areas of the oral and maxillofacial region by enhancing the expression of bone marker genes [18, 19].

Therefore, this study aimed to evaluate the bone formation ability of human demineralized dendritic matrix combined with platelet-rich fibrin (PRF) and recombinant human bone morphogenetic protein-2 (rhBMP-2) in rabbit calvarial bone defects by histopathological and histomorphometric analyses.

\section{Materials and methods \\ Subjects and materials \\ Experimental animals}

Twelve healthy male rabbits (New Zealand, white rabbits) which weighed around $3.0-4.0 \mathrm{~kg}$ were included in the experiments. This study was approved by Kronex Co., Ltd. Animal Experimental Ethics Committee. The approval number of the animal experiment is CRONEXIACUC:2013005.

\section{Bone grafting materials}

The extracted teeth were immersed in $70 \%$ ethyl alcohol and were delivered to a specialized treatment company, the Korea Tooth Bank Co. (Seoul, Korea), and separated into the crowns and roots after removing foreign materials such as soft tissue and plaque attached to each tooth, and then pulverization of the teeth was performed. After immersing 1-2-mm pulverized particles into distilled water and a hydrogen oxide solution, they were washed with an ultrasonic cleaner to remove the remaining foreign materials, and washed particles were dehydrated, followed by defatting using ethyl alcohol. After the procedure described above, the particles underwent lyophilization and were sterilized with ethyleneoxide gas, and they arrived at the lab in a wrapped container before they were used for bone grafting.

\section{Signaling molecules to promote the bone formation ability}

Preparation of platelet-rich fibrin (PRF) When the rabbit was restrained so that it would not move, $8 \mathrm{ml}$ of blood was collected directly from the ear with a syringe, and then $8 \mathrm{cc}$ of blood was centrifuged immediately without putting it in a separate container for the addition of any substance or manipulation. Blood samples were centrifuged at $400 \mathrm{G}$ for $10 \mathrm{~min}$ (BMS, Korea).

Preparation of recombinant human bone morphogenetic protein-2 (rhBMP-2) The recombinant human bone morphogenetic protein-2 (rhBMP-2) (Cowellmedi Co, Korea) with a concentration of $2 \mathrm{mg} / \mathrm{ml}$ was added to $0.03 \mathrm{~g}$ of DDM by the dip dry method and kept in a sterile container in the frozen state.

\section{Methods}

Surgery of experimental animals

Each rabbit received an intramuscular injection of Zoletil $50(0.5 \mathrm{ml} / \mathrm{kg})$ (Virvac, France) and Xilazine $(0.25 \mathrm{mg} / \mathrm{kg})$ (Rompum, Bayer, Leverkusen, Germany) for general anesthesia. The calvarium was exposed by making a median incision in the skin of the scalp from the anterior 
part of the rabbit's frontal bone to the posterior part. A circular defect of $8 \mathrm{~mm}$ in diameter and $3 \mathrm{~mm}$ in depth was created in the exposed calvarium using a trephine bur with $8 \mathrm{~mm}$ inner diameter and $9 \mathrm{~mm}$ outer diameter (3i, Palm Beach Gardens, FL, USA). In the control group, manual pressure hemostasis was performed with gauze without any treatment of the circular defect, and in experimental group 1, calvarial bone defects were treated using DDM as a sole grafting material. In experimental group 2, bone defects were treated with a mixture of PRF and DDM. In experimental group 3, bone defects were treated using DDM with absorbed rhBMP2 (Fig. 1). Then, after covering the bone defect with the scalp skin, suturing was performed using 4-0 coated Vicryl $^{\circ}$ sutures (Polyglactin 910, braided absorbable suture, Ethicon, Johnson \& Johnson Int., Edinburgh, UK), and sutures were removed 1 week after surgery.

\section{Histopathological analysis}

To make demineralized samples, three rabbits were sacrificed immediately after surgery and at 2, 4, and 8 weeks postoperatively, respectively, then the skull was detached, and tissue sections of surgical sites were obtained with a hard tissue cutting machine. After the collected tissue slices were sufficiently fixed with $70 \%$ ethyl alcohol and washed with running water, fixation was performed with $10 \%$ neutral formalin for the preservation of proteins in the tissue. Then, the tissues were dehydrated in $5 \%$ nitric acid solution for 5 days and they were embedded in paraffin. Finally, an incision was made to a thickness of $3 \mu \mathrm{m}$ in a transverse direction of the calvarium, and after hematoxylin and eosin (H\&E) staining and Masson's trichrome (M-T) staining, histological examination was carried out using an Olympus BX-51 optical microscope (Olympus Co., Tokyo, Japan). The

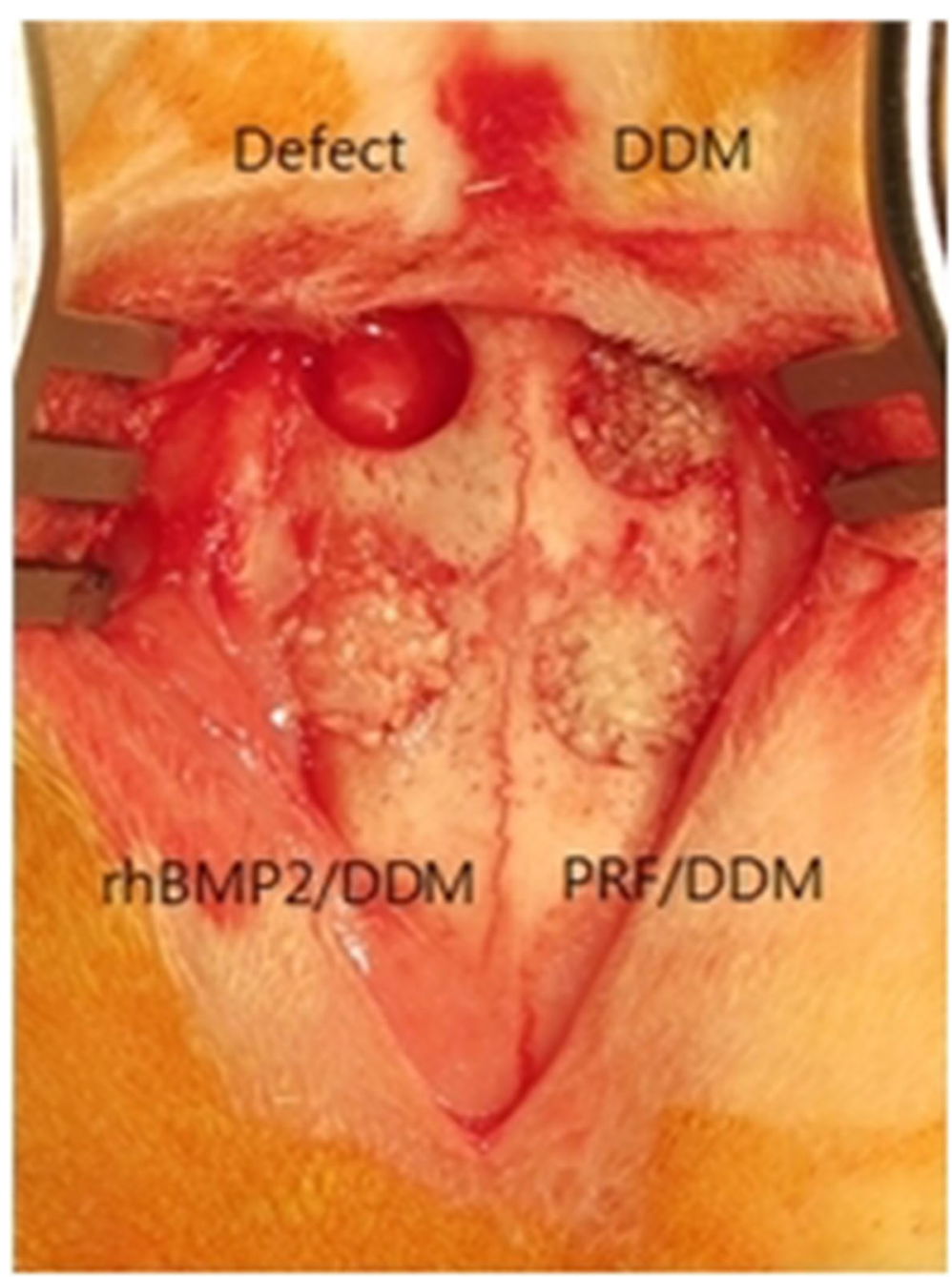

Fig. 1 Experimental design. The control group received manual pressure hemostasis with gauze and did not receive any graft into the calvarial defect. In experimental group 1, bone defects were treated using DDM as a sole grafting material. Experimental group 2 were treated with a mixture of PRF and DDM. Experimental group 3 were treated using DDM with absorbed rhBMP-2 
stained tissue slides were made with a digital camera attached to a scientific microscope, using the SPOT Advanced $^{\mathrm{TM}}$ software program (Olympus Co., Tokyo, Japan)

\section{Histomorphometric analysis}

At 2, 4, and 8 weeks after surgery, two tissue slides for each of the control and experimental groups 1,2, and 3 were made. Microscopic images of the surgical sites were taken by randomly selecting four areas of the center portion of the defect at $100 \times$ magnification. Then, using 24 images of each group per week, the ratio of newly formed mineralized bone (new bone formation) to the entire defect area in the slide images was calculated using the Image Pro plus ${ }^{\oplus}$ image analysis program. The area of newly formed bone was defined as the area up to the boundary of newly formed bone including mineralized bone, fibrous connective tissue, and new blood vessels. Statistical analysis was carried out using SSPS ver. 17.0 (SPSS, Chicago, IL, USA). A MannWhitney $U$ test was conducted, and the level of significance was defined as $P<0.05$.

\section{Results \\ Histopathological findings \\ The control group}

Findings at 2 weeks The defect was filled with irregular, thin, fibrous connective tissue, and bleeding was observed. New bone was not detected (Figs. 2A and 3A).

Findings at 4 weeks Partially aligned connective tissues were observed in the defect, a minimal degree of new bone formation and osteoid tissue began to appear in

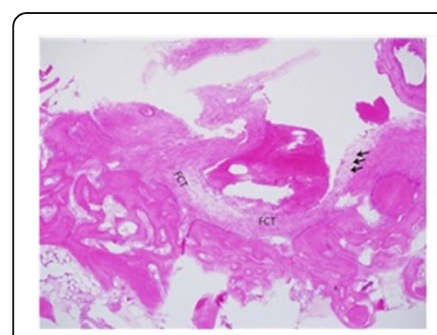

A

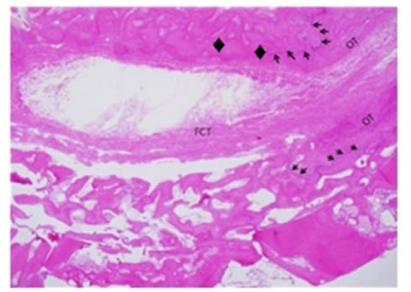

E

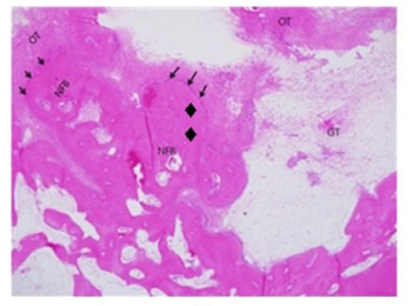

I

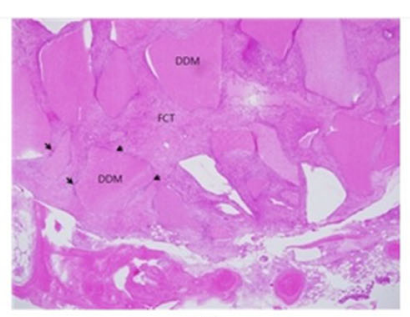

B

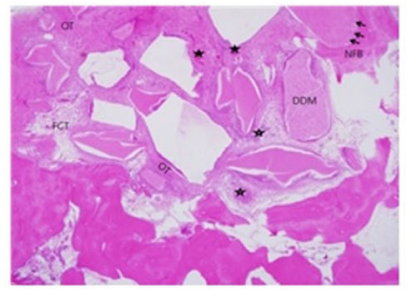

F

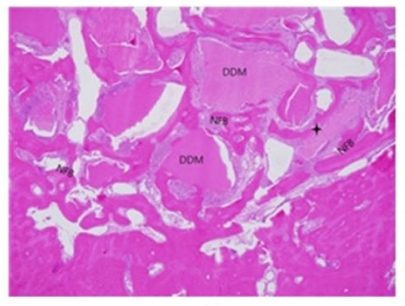

J

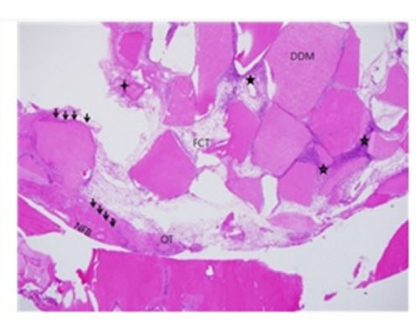

C

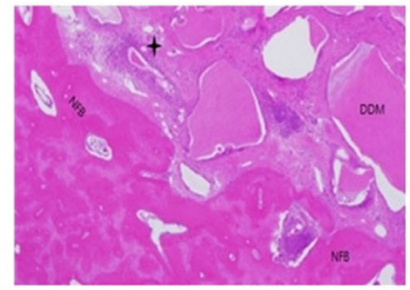

G

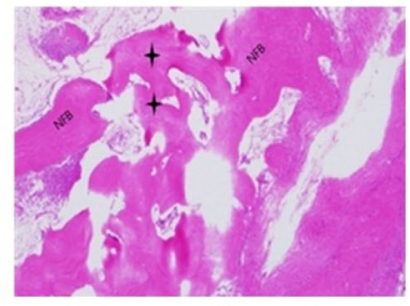

K

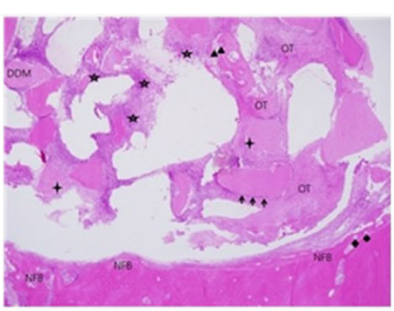

D

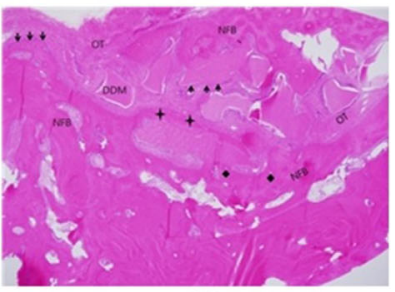

H

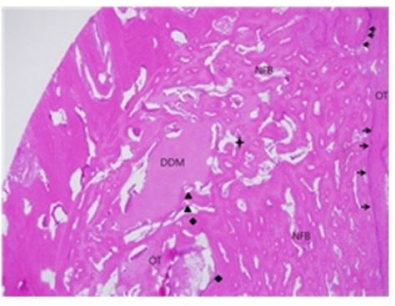

L

Fig. 2 Hematoxylin and eosin stain (original magnification $\times 40$ ). A Histologic finding of the control group after 2 weeks (FCT fibrous connective tissue). B Histologic finding of the DDM group after 2 weeks ( $\rightarrow$ osteoblast, FCT fibrous connective tissue). C Histologic finding of the PRF/DDM group after 2 weeks $(\rightarrow$ osteoblast, OT osteoid tissue, $\star$ blood vessel, FCT fibrous connective tissue, NFB newly formed bone). D Histologic finding of the rhBMP2/DDM group after 2 weeks $(\rightarrow$ osteoblast, OT osteoid tissue, is cluster of fibroblast, $\bullet$ osteocyte, $:$ resorbed DDM, $\boldsymbol{\Delta}$ osteoclast, NFB newly formed bone). E Histologic finding of the control group after 4 weeks $(\rightarrow$ osteoblast, $\bullet$ osteocyte, OT osteoid tissue, FCT fibrous connective tissue). F Histologic finding of the DDM group after 4 weeks $(\rightarrow$ osteoblast, OT osteoid tissue, $\star$ blood vessel, $i$ cluster of fibroblast, FCT fibrous connective tissue, NFB newly formed bone). G Histologic finding of the PRF/DDM group after 4 weeks (: resorbed DDM, OT osteoid tissue, NFB newly formed bone). $\mathbf{H}$ Histologic finding of the rhBMP2/DDM group after 4 weeks $(\rightarrow$ osteoblast, OT osteoid tissue, $\bullet$ osteocyte, : resorbed DDM, NFB newly formed bone). I Histologic finding of the control group after 8 weeks ( $\rightarrow$ osteoblast, $\bullet$ osteocyte, GT granulation tissue, NFB newly formed bone). J Histologic finding of the DDM group after 8 weeks (NFB newly formed bone). $\mathbf{K}$ Histologic finding of PRF/DDM group after 8 weeks (: resorbed DDM, NFB newly formed bone). L Histologic finding of the rhBMP2/DDM group after 8 weeks (: resorbed DDM, $\rightarrow$ osteoblast, OT osteoid tissue, $\bullet$ osteocyte, : resorbed DDM, $\boldsymbol{\Delta}$ osteoclast, NFB newly formed bone) 


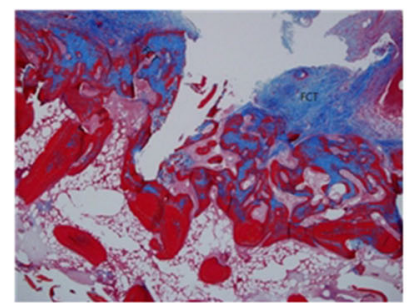

A

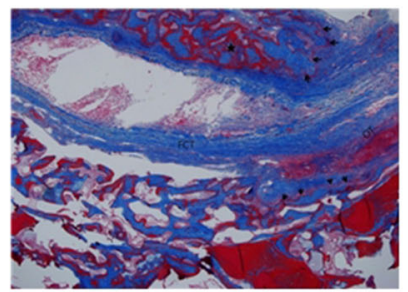

E

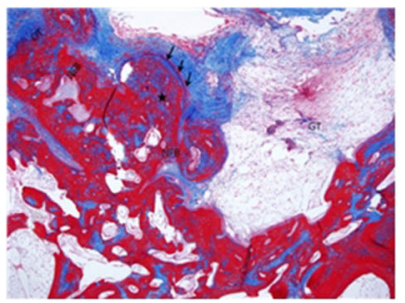

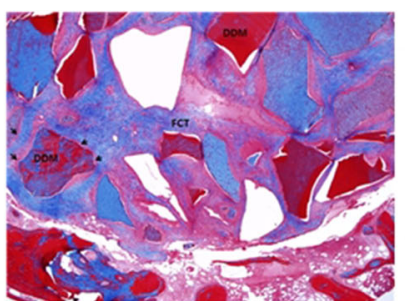

B

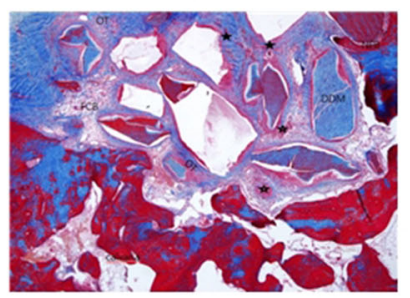

F

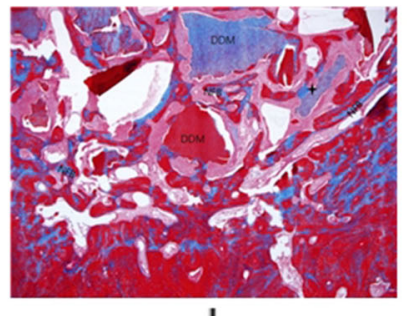

J

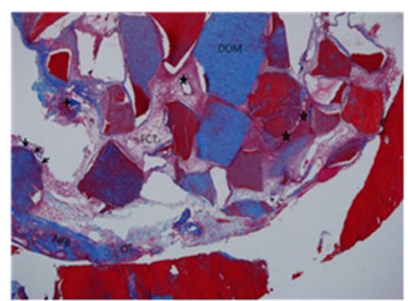

C

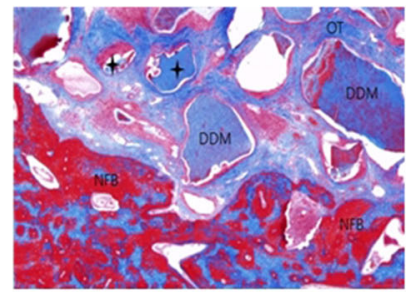

G

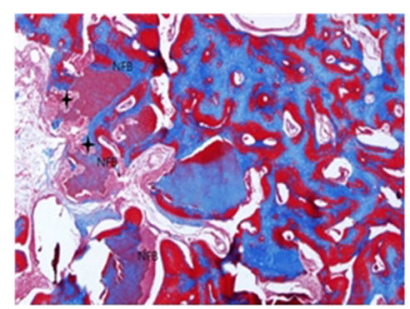

K

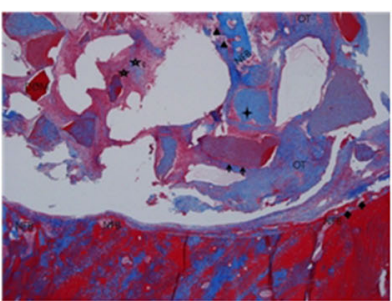

D

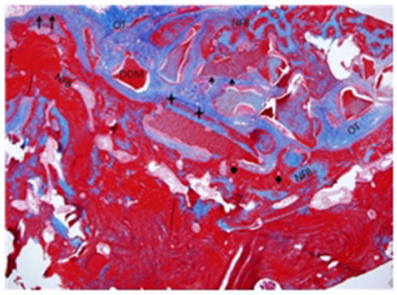

$\mathrm{H}$

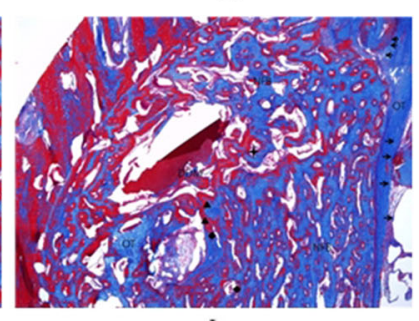

L

Fig. 3 MT stain (original magnification $\times 40$ ). A Histologic finding of the control group after 2 weeks (FCT fibrous connective tissue). B Histologic finding of the DDM group after 2 weeks ( $\rightarrow$ osteoblast, FCT fibrous connective tissue). C Histologic finding of the PRF/DDM group after 2 weeks $(\rightarrow$ osteoblast, OT osteoid tissue, $\star$ blood vessel, : resorbed DDM, FCT fibrous connective tissue, NFB newly formed bone). D Histologic finding of the rhBMP2/DDM group after 2 weeks $(\rightarrow$ osteoblast, OT osteoid tissue, 2 cluster of fibroblast, $\bullet$ osteocyte, : resorbed DDM, $\boldsymbol{\Delta}$ osteoclast, NFB newly formed bone). E Histologic finding of the control group after 4 weeks $(\rightarrow$ osteoblast, $\star$ osteocyte, OT osteoid tissue, FCT fibrous connective tissue). F Histologic finding of the DDM group after 4 weeks ( $\rightarrow$ osteoblast, OT osteoid tissue, $\star$ blood vessel, $i$ cluster of fibroblast, FCT fibrous connective tissue, NFB newly formed bone). G Histologic finding of the PRF/DDM group after 4 weeks (: resorbed DDM, OT osteoid tissue, NFB newly formed bone). $\mathbf{H}$ Histologic finding of the rhBMP2/DDM group after 4 weeks ( $\rightarrow$ osteoblast, OT osteoid tissue, $\bullet$ osteocyte, : resorbed DDM, NFB newly formed bone). I Histologic finding of the control group after 8 weeks ( $\rightarrow$ osteoblast, $\star$ osteocyte, GT granulation tissue, NFB newly formed bone). J Histologic finding of the DDM group after 8 weeks (: resorbed DDM, NFB newly formed bone). $\mathbf{K}$ Histologic finding of the PRF/DDM group after 8 weeks (: resorbed DDM, NFB newly formed bone). L Histologic finding of the rhBMP2/DDM group after 8 weeks $(\rightarrow$ osteoblast, OT osteoid tissue, $\bullet$ osteocyte, : resorbed DDM, $\boldsymbol{\Delta}$ osteoclast, NFB newly formed bone)

the defect margin, and osteocytes were observed along the defect margin (Figs. 2E and 3E).

Findings at 8 weeks Relatively well-aligned connective tissue with uniform density was observed in the defect, and granulation tissue was detected in the center of the defect. New bone formation was identified only in the defect margin, but features of immature bones such as a large medullary cavity were found (Figs. 2I and 3I).

\section{Experimental group 1 (the DDM group)}

Findings at 2 weeks The defect area was mostly filled with DDM, and fibrous connective tissues with osteoblasts were observed among the DDM particles (Figs. 2B and $3 \mathrm{~B})$.
Findings at 4 weeks The degree of new bone formation in the defect margin was higher compared to the control group. Osteoid tissue was also detected across the defect area, and bone formation was actively progressing (Figs. $2 \mathrm{~F}$ and $3 \mathrm{~F})$.

Findings at 8 weeks New bone was formed as a large portion of the DDM which filled the defect area was absorbed. As bone maturation and bone remodeling progressed in the defect margin, new bone and existing bone were found to coexist. As the calcification of newly formed bone progressed further, bony trabecula became more dense and a mature pattern of bony trabecula similar to that of the normal bone was observed. Compared to the control group, osteoinduction was observed (Figs. 2J and 3J). 


\section{Experimental group 2 (the PRF/DDM group)}

Findings at 2 weeks The area around DDM particles was found to be surrounded by a large amount of osteoblasts, and particles of absorbed DDM were also observed along with osteoclasts. New bone formation was actively progressing in the defect margin and neovascularization was observed among DDM particles (Figs. 2C and $3 \mathrm{C})$.

Findings at 4 weeks Compared with experimental group 1, a large amount of new bone formation was observed in the defect margin, and absorbed DDM particles were found together with osteoclasts. Osteoid tissue was observed among DDM particles, indicating that bone formation was actively progressing (Figs. 2G and $3 G)$.

Findings at 8 weeks Compared with experimental group 1, new bone was formed farther from the defect margin, new bone extended into the area where collagen bundles and DDM were completely absorbed, and gradual calcification was also observed. In particular, as osteoid tissue and cancellous bone decreased, the lamellae of bone matrix, which are observed in mature bone tissue, were observed. Compared with the control group, osteoinduction was observed (Figs. 2K and 3K).

\section{Experimental group 3 (the rhBMP-2/DDM group)}

Findings at 2 weeks New bone formation was observed not only in the defect margin but also in the central part of the defect. Absorbed DDM particles along with more osteoclasts were observed compared to experimental group 2 (Figs. 2D and 3D).

Findings at 4 weeks Compared to experimental group 2 , the degrees of new bone formation and bone remodeling were higher, showing that they progressed faster, and it was found that bone tissue formation and calcification were gradually progressing in the way that bone tissue was surrounded by a newly formed bone matrix in the periphery of DDM, the absorbed bone graft material (Figs. $2 \mathrm{H}$ and $3 \mathrm{H}$ ).

Findings at 8 weeks A large amount of new bone formed not only in the defect margin but also in the entire defect area including the central part of the defect. The degree of new bone formation and calcification were higher than experimental group 2, showing that they were progressing faster. Also, the lamellae of bone matrix, which are observed in mature bone tissue, were more distinctly visible. Compared to the control group, osteoinduction was observed (Figs. 2L and 3L).

\section{Histomorphometric results}

The amount of new bone formation in the calvarial defect was 3.2 observed in ma, and 8.1nt of new bon, and 8 weeks, respectively, in the control group, and 20.3as 3.2 observed in mature bone tissue, we, and 8 weeks, respectively, in the DDM group. Also, it was $22.7 \pm 10.2 \%$, $31.2 \pm 11.7 \%$, and $46.5 \pm 15.1 \%$ at 2,4 , and 8 weeks, respectively, in the PRF/DDM group, and $26.922 .7 \pm 10.2 \%$, $31.2 \pm 11.7 \%, 58.78$ weeks, resp, and 8 weeks, respectively, in the rhBMP-2/DDM group. The measurements of new bone formation showed that there was not a statistically significant difference between the PRF/DDM group and the DDM group at 2,4 , and 8 weeks. (Table 1). On the other side, there was a statistically significant difference between the rhBMP-2/DDM group and the DDM group at 4 and 8 weeks $(P<0.05)$ (Table 1$)$.

\section{Discussion}

The rabbit calvarial defect model is known to be useful for analyzing and evaluating the bone formation ability of bone grafting materials because it has better accessibility and reproducibility than other animal models and is easy to handle. The calvarial bone consists of inner and outer tables (cortical bone) and trabecular bone between them, so it has the advantage that it is biomechanically similar to human jaw bones. Experiments were conducted under the same conditions and rabbits were kept under the same conditions, including solid feed and separate indoor rooms (average room temperature of $22^{\circ} \mathrm{C}$, light-dark cycles of 12:12 h). Twelve male rabbits were used as subjects and female rabbits were excluded from the experiment because hormonal changes or pregnancy of females may affect the experimental results. Circular bone defects with a diameter of $8 \mathrm{~mm}$, which is the critical size defect (CSD) in rabbits, were created in the calvaria. The CSD refers to the smallest size defect in an animal which shows less than $10 \%$ bone regeneration when left untreated [20]. In addition, when resected bone tissue is removed after creating a circular bone defect with a diameter of $8 \mathrm{~mm}$ and a depth of 3 $\mathrm{mm}$ using a trephine bur with $8 \mathrm{~mm}$ inner diameter and $9 \mathrm{~mm}$ outer diameter (3i, Palm Beach Gardens, FL, USA), the cranial dura mater of the rabbit is sometimes exposed. In such cases, care was taken to preserve the cranial dura mater because it plays an important role in the bone formation of bone graft materials.

Tooth ash powder, a previously developed bone grafting material reported in prior studies, is produced by pulverizing extracted tooth into powder after hightemperature treatment to inhibit immune responses against bone grafts, so it has been reported to exhibit only osteoconductive capacity because it consists only of minerals. In contrast, DDM used in this study contained many bone growth factors, including type I collagen and 
Table 1 New bone formation

\begin{tabular}{llll}
\hline Group & 2 weeks & 4 weeks & 8 weeks \\
\hline Control group (defect) & $3.2 \mathrm{fect}$ & $5.8 \mathrm{fect}$ & $8.1 \mathrm{fect}$ \\
Experimental group 1 (DDM) & 20.3 rime & 30.6 rimen & 45.1 rimen \\
Experimental group 2 (PRF/DDM) & 22.7 rimen & 31.2 rimen & 46.5 rimen \\
Experimental group 3 (rhBMP-2/DDM) & 26.9 rimen & $42.7 \pm 13.8 \star$ & $58.7 \pm 19.8 \star$ \\
\hline
\end{tabular}

`Statistically significant difference compared to the DDM group $(P<0.05)$ (each group averagefstandard deviation, \%)

BMP preserved in the dentin of teeth, and thus was shown to exhibit osteoinductive capacity as well as osteoconductive capacity. The histological analysis of this study also showed that osteoinduction occurred in all the experimental groups, different from the control group. In all the experimental groups, osteoblasts gradually formed from bone tissue toward DDM, the bone grafting material, and at the same time, new bone tissue was formed directly from the peripheral area of DDM.

In the present study, histomorphometric analysis of the amount of new bone formation did not show statistically significant differences between the PRF/DDM group and the DDM group. New bone formation was observed farther away from the defect margin in the PRF/DDM group, compared to the DDM group. Moreover, new bone extended into the area where collagen bundles and DDM were absorbed and gradual mineralization was observed in the PRF/DDM group.

In 1965 and 1971, Urist [14, 15] reported that heterotrophic ossification occurred around the bone graft material when the demineralized bone flap was transplanted in the subcutaneous tissue of rats, and the specific type of proteins in bone tissue which contribute to bone formation was named bone morphogenetic protein (BMP). In 2019 and 2020, BMP-2 increases the activity of alkaline phosphatase and has been shown to effectively stimulate bone formation experimentally and clinically in the bone defect areas of the oral and maxillofacial region by enhancing the expression of bone marker genes $[18,19]$.

In this study, histological analysis showed that in contrast to the DDM group, the PRF/DDM group and the rhBMP-2/DDM group showed new bone was directly formed from the peripheral area of DDM. The PRF/ DDM group did not show a significantly higher degree of new bone formation in bone defects than the DDM group at 2, 4, and 8 weeks postoperatively.

On the other side, a larger amount of new bone formed in the entire defect area including the central part of the defect as well as the defect margin in the rhBMP-2/DDM group, compared to the DDM group. Also, the rhBMP-2/DDM group showed higher degrees of new bone formation and calcification, and the lamellae of bone matrix, which are observed in mature bone tissue, were more distinctly visible in the rhBMP-2/
DDM group. Moreover, the histomorphometric analysis revealed that the amount of new bone formation in the calvarial defect area was significantly higher in the rhBMP-2/DDM group than in the DDM group at 4 and 8 weeks after surgery $(P<0.05)$.

\section{Conclusion}

Demineralized dentin matrix (DDM) is a material with great potential as an excellent carrier for the maintenance and controlled-release of recombinant human bone morphogenetic protein-2 (rhBMP-2), which has been recently been receiving wide attention as a type of signaling molecules to promote bone formation ability.

\section{Abbreviations \\ DDM: Demineralized dentin matrix; rhBMP-2: Recombinant human bone morphogenetic protein-2; PRF: Platelet-rich fibrinogen; PDGF: Platelet-derived growth factors; BMP: Bone morphogenetic proteins; EGF: Epidermal growth factors; FGF: Fibroblast growth factors; PRP: Platelet-rich plasma; \\ FDBA: Freeze-dried bone allograft; DFDBA: Demineralized freeze-dried bone allograft; CSD: Critical size defect; H\&E staining: Hematoxylin and eosin \\ staining; M-T staining: Masson's trichrome staining; TGF: Transforming growth} factors

\section{Acknowledgements}

Not applicable.

\section{Authors' contributions}

KBJ collected the data and wrote the manuscript. LJH revised the original manuscript and edited the figures. KSK did the critical review. The authors read and approved the final manuscript.

Funding

This work was carried out without funding support.

Availability of data and materials

Data sharing is not applicable to this article since no dataset was generated or analyzed during the current study.

\section{Declarations}

Ethics approval and consent to participate

IRB was exempted for this study because of a retrospective chart review.

Consent for publication

Written informed consent was obtained from the patient for publication of this report and accompanying images.

\section{Competing interests}

The authors declare that they have no competing interests. KBJ and $\mathrm{LH}$ are editorial board members of "Maxillofacial Plastic and Reconstructive Surgery."

\section{Author details}

${ }^{1}$ Seoul Boston Dental Clinic, 3rd Floor, Geumgang Plaza, 49, Cheongsa-ro, Uijeongbu-si, Gyeonggi-do, Republic of Korea. ${ }^{2}$ Department of 
Anesthesiology and Pain Medicine, College of Medicine, Dankook University, 201, Manghyang-ro, Dongnam-gu, Cheonan-si, Chungcheongnam-do, Republic of Korea. ${ }^{3}$ Department of Oral and Maxillofacial Surgery, College of Dentistry, Dankook University, 119, Dandae-ro, Dongnam-gu, Cheonan-si, Chungcheongnam-do 31116, Republic of Korea.

Received: 21 May 2021 Accepted: 31 August 2021

Published online: 09 September 2021

\section{References}

1. Zhang S, Li X, Qi Y, Ma X, Qiao S, Cai H, Zhao BC, Jiang HB, Lee ES (2021) Comparison of autogenous tooth materials and other bone grafts. Tissue Eng Regen Med. 18(3):327-341. https://doi.org/10.1007/s13 770-021-00333-4

2. Gual-Vaqués $P$, Polis-Yanes C, Estrugo-Devesa A, Ayuso-Montero R, Mari-Roig A, López-López J (2018) Autogenous teeth used for bone grafting: a systematic review. Med Oral Patol Oral Cir Bucal 23(1): e112-e119

3. Um IW, Kim YK, Mitsugi M (2017) Demineralized dentin matrix scaffolds for alveolar bone engineering. J Indian Prosthodont Soc. 17(2):120-127

4. Tazaki J (2008) Autograft of human tooth and demineralized dentin matrices for bone augmentation archives of bioceramics research. Proceeding of the Asia BioCeramics 8:181-184

5. Deuel TF, Kawahara RS, Mustoe TA, Pierce GF (1991) Growth factors and wound healing: platelet-derived growth factor as a model cytokine. Annu Rev Med 42(1):567-584. https://doi.org/10.1146/annurev.me.42.020191.003 031

6. Deuel TF (1991) Structural and functional diversity of the platelet-derived growth factor. Cur Opin Bioechnol 2(6):802-806. https://doi.org/10.1016/ S0958-1669(05)80110-7

7. Kim SY, Kim YK, Park YH, Park JC, Ku JK, Um IW, Kim JY (2017) Evaluation of the healing potential of demineralized dentin matrix fixed with recombinant human bone morphogenetic protein-2 in bone grafts. Materials (Basel). 10(9):1049. https://doi.org/10.3390/ma10091049

8. Mohan S, Baylink DJ (1991) Bone growth factors. Clin Orthop Relat Res 263(263):30-48. https://doi.org/10.1097/00003086-199102000-00004

9. Streiff MB, Ness (2002) Acquired FV inhibitors: a needless iatrogenic complication of bovine thrombin exposure. Transfusion 42(1):18-26. https:// doi.org/10.1046/j.1537-2995.2002.00011.x

10. Kajitani M, Ozdmir A, Aguinaga M et al (2000) Severe hemorrhagic complication due to acquired factor $V$ inhibitor after single exposure to bovine thrombin product. J Card Surg 15(6):378-382. https://doi.org/1 0.1111/j.1540-8191.2000.tb01296.x

11. Dohan DM, Choukroun J, Diss A, Dohan SL, Dohan AJJ, Mouhyi J, Gogly B (2006) Platelet-rich fibrin (PRF): a second-generation platelet concentrate. Part III: leucocyte activation: a new feature for platelet concentrates? Oral Surg Oral Med Oral Pathol Oral Radiol Endod 101(3):e51-e55. https://doi. org/10.1016/.t.tripleo.2005.07.010

12. Choukroun J, Diss A, Simonpieri A, Girard MO, Schoeffler C, Dohan SL, Dohan AJJ, Mouhyi J, Dohan DM (2006) Platelet-rich fibrin (PRF): a secondgeneration platelet concentrate. Part V: 15 histologic evaluations of PRF effects on bone allograft maturation in sinus lift. Oral Surg Oral Med Oral Pathol Oral Radiol Endod 101(3):299-303. https://doi.org/10.1016/j.tripleo.2 005.07.012

13. Dohan DM, Choukroun J, Diss A, Dohan SL, Dohan AJJ, Mouhyi J, Gogly B (2006) Platelet-rich fibrin (PRF): a second-generation platelet concentrate. Part II: platelet-related biologic features. Oral Surg Oral Med Oral Pathol Oral Radiol Endod 101(3):e45-e50. https://doi.org/10.1 016/j.tripleo.2005.07.009

14. Urist MR (1965) Bone formation by auto induction. Science 150(3698):893899. https://doi.org/10.1126/science.150.3698.893

15. Urist MR, Strates BS (1971) Bone morphogenetic protein. J Dent Res 50(6): 1392-1406. https://doi.org/10.1177/00220345710500060601

16. Daluiski A, Engstrand T, Bahamonde ME, Gamer LW, Agius E, Stevenson SL, Cox K, Rosen V, Lyons KM (2001) Bone morphogenetic protein-3 is a negative regulator of bone density. Nat Genet 27(1):84-88. https://doi.org/1 $0.1038 / 83810$

17. Gazit D, Turgeman G, Kelley P, Wang E, Jalenak M, Zilberman Y, Moutsatsos I (1999) Engineered pluripotent mesenchymal cells integrate and differentiate in regenerating bone: a novel cell-mediated gene therapy. J Gene Med 1(2):
121-133. https://doi.org/10.1002/(SICl)1521-2254(199903/04)1:2<121::AIDJGM26>3.0.CO;- $2-5$

18. Um IW, Ku JK, Lee BK, Yun PY, Lee JK, Nam JH (2019) Postulated release profile of recombinant human bone morphogenetic protein-2 (rhBMP-2) from demineralized dentin matrix. J Korean Assoc Oral Maxillofac Surg. 45(3):123-128. https://doi.org/10.5125/jkaoms.2019.45.3.123

19. Um IW, Ku JK, Kim YK, Lee BK, Leem DH (2020) Histological review of demineralized dentin matrix as a carrier of rhBMP-2. Tissue Eng Part B Rev. 26(3):284-293. https://doi.org/10.1089/ten.teb.2019.0291

20. Takagi K, Urist MR (1982) The reaction of the dura to bone morphogenetic protein (BMP) in repair of skull defect. Ann Surg 196(1):100-109. https://doi. org/10.1097/00000658-198207000-00020

\section{Publisher's Note}

Springer Nature remains neutral with regard to jurisdictional claims in published maps and institutional affiliations.

\section{Submit your manuscript to a SpringerOpen ${ }^{\circ}$ journal and benefit from:}

- Convenient online submission

- Rigorous peer review

- Open access: articles freely available online

- High visibility within the field

- Retaining the copyright to your article

Submit your next manuscript at $\boldsymbol{\nabla}$ springeropen.com 